\section{Human genome dispute}

SIR - Your article "Secrecy and the bottom line" (Nature 354, 96; 1991) seriously misrepresents the Medical Research Council (MRC) in a number of respects. May I try to set the record straight?

The MRC is accused of secrecy with respect to the identity of sequences of fragments of cDNA. Before the decision of the Office of Technology Transfer at the National Institutes of Health (NIH) to file patents on its cDNA sequences, MRC intended to publish openly its sequences in its database. That remains MRC's preferred position. MRC believes that filing patents on cDNA sequences is counterproductive to the interest of industry and would not facilitate the delivery of long-term health care benefits, a view also stated by representatives of industry. However, following the patent application by NIH, we feel compelled to retain our option to file patents; the temporary withholding of the data was intended only to allow us time to react to the NIH initiative.

A second major misrepresentation is embodied in "holding its sequences secret while it prepares to sell them to industry". Access to the database is free to academics on the understanding that they provide information back into the database, as they generate pertinent facts. No such obligation is placed on industry which instead is asked to pay a modest subscription towards costs. This relationship between provision of service and charge is completely consistent with government policy. Reaction from industry to our proposals for a subscription scheme - both in principle and at the levels of charging imposed - has been

\section{Playing the game}

SIR - Christopher Anderson, in his report of Ohio State University's decision to withdraw from the Columbus telescope project (Nature 353, 97; 1991), said the announcement came as Ohio State's (American) football team arrived in Tucson for a game and suggested that, to make matters worse, "the Ohio State team ... trounced the Arizona Wildcats, 38-14".

Is Nature suggesting that the outcome of that game (which took place incidentally in Columbus, Ohio, not in Tucson, Arizona) was or should be linked to a decision on the future of academic research, or that the gentlemanly thing to do would have been to lose the game?

University Communications,

EARLE M. HOLLAND

Ohio State University,

Columbus, Ohio 43212-1153, USA warm and has encouraged us to continue.

Medical Research Council,

D. A. REES

(Secretary)

20 Park Crescent, London W1N 4AL, UK

The word "misrepresentation" hardly seems appropriate, for there is no discordance on facts. MRC may have intended to make its cDNA data freely available to academics, but had not done so in midNovember (and will not now do so until the patent issue is resolved); is a "secret" to be called something else if its perpetrators intend that it should eventually be something else? And nothing in the News article complained of was intended to suggest that MRC is acting outside the framework of (British) government policy, but merely that that policy may not be in the best interests of science and discovery. - Editor, Nature.

SIR - Contrary to your remark (Nature 354, 171; 1991), HUGO (the Human Genome Organisation) is very much alive. Established by the community of genome scientists three years ago, HUGO's central concern has been the coordination of scientific activities at the level of both single chromosomes and the whole genome.

A research project involving thousands of researchers around the world and generating enormous amounts of data poses immense problems of communication. Following Human Gene Mapping (HGM) Workshop 11 in London this summer, there is now clear agreement on the way forward. The scale of the task means that it is sensible to work on each chromosome separately, by means of a series of 'Single Chromosome Workshops'. HUGO is coordinating the organization of these meetings in location and geographical spread, timing and funding mechanism. Our guidelines should help with the planning and running of these workshops, particularly when common procedures can save time and effort.

We also plan annual Chromosome Coordination Meetings (CCMs) bringing together small numbers of people from groups concerned with each chromosome to discuss common problems and policies. The 1992 CCM will be in Baltimore, Maryland, and HUGO has just agreed with the Japanese genome community that it will host CCM93.

Every other year, the CCMs will be associated with restyled Human Genome Mapping Workshops, with wide interdisciplinary participation, allowing coordination of information on mapping and sequencing, assessment of overall progress on the Human Genome Project and discussion of the broader biological ques- tions it will provoke.

In support of these developments, HUGO is concerned with the development and management of databases, DNA clones, cell lines and other biological reagents with the aim (among others) of ensuring that the availability of materials and the arrangements for their distribution are adequate. We are also compiling central registers of information about genome meetings, databases, projects, DNA collections and cell lines, and are beginning to act as a clearing-house for this material.

On the wider front, the recent appointment of Nancy Wexler and Alain Pompidou as co-chairs of an ethics committee signals HUGO's readiness to be the focus for international discussions of the social, legal and ethical issues arising. Meanwhile, HUGO's development of an international research programme on Human Genetic Diversity reflects interest in the functional significance of the data that will be generated.

You may be interested that the specific issues discussed in your article were first raised at a meeting convened by HUGO in August this year, during HGM11, when there was a frank discussion between representatives of most cDNA groups and others about the storage of and access to cDNA sequence data. UGO is concerned that if the NIH patent applications for cDNA sequences are approved, scientific exchange will be harmed and the transfer of important technology for the benefit of human health will be impeded. We do not, of course, oppose the patenting of genetic information whose utility has been demonstrated, but rather the patenting of short sequences from randomly isolated portions of a gene encoding a protein of unknown function.

Apart from the difficulty of deciding on the novelty and utility of such patent applications, it seems likely that approval of them would cause competition between laboratories to escalate, discourage the sharing of information and promote a climate of genome 'ownership', all of which conflict with HUGO's aim of fostering international collaboration so as to avoid needless competition and duplication. We hope that governments will pay attention to these issues, and that they will develop patent policies that, while allowing developments based on the use of sequences to be appropriately protected, will permit the widespread sharing of materials and information and not jeopardize the Human Genome Project as a major international collaboration.

WALTER BODMER (President of HUGO)

Imperial Cancer Research Fund. PO Box 123, Lincoln's Inn Fields. London WC2A 3PX, UK 